\title{
Utilizing Focused Ion Beam (FIB) and Transmission Electron Microscopy (TEM) for Failure Analysis of Char Deposits Obtained From Space Shuttle Columbia Window Debris
}

\author{
M. Clara Wright*, Roy Christoffersen**, Zia Rahman** and Steve J. McDanels* \\ * National Aeronautics and Space Administration, Materials Science Division, Mail Code: NE- \\ L1, Kennedy Space Center, FL 32899 \\ ** Jacobs Technology at Johnson Space Center, Mail Code: KR, 2101 NASA Parkway, \\ Houston, TX, 77058 \\ This document was prepared under the sponsorship of the National Aeronautics and Space Administration. Neither the United \\ States government nor any person acting on behalf of the United States government assumes any liability resulting from the use \\ of the information contained in this document, or warrants that such use will be free from privately owned rights.
}

Window pane fragments removed from the damaged overhead window frames of Space Shuttle Columbia were analyzed as part of the Spacecraft Crew Survival Integrated Investigation Team (SCSIIT) [1]. Cockpit windows and related hardware were among the 84,000+ pieces of debris recovered after the unfortunate breakup of Columbia on February 1, 2003. The breakup occurred when the vehicle's velocity was in excess of Mach 18, at an altitude of over 60,960 m and the resultant debris experienced temperatures in excess of $1750^{\circ} \mathrm{C}$ [2]. The Columbia Accident Investigation Board (CAIB) determined that foam debris impact from the external tank breached the left hand wing leading edge reinforced carbon-carbon (RCC) panels during launch, which led to a considerable thermal event during reentry [3]. The SCSIIT was chartered to perform a comprehensive analysis of the accident focusing on factors and events affecting crew survival, and to develop recommendations for improving crew survival for all future human space flight vehicles. A sub-team to the SCSIIT analyzed the effect of the plasma reentry environment on selected orbiter structural and sub-structural materials [4].

A methodology for analyzing deposited material on space shuttle Columbia windows (Figure 1) was employed to further understand the sequence of events which occurred during the loss of the vehicle. This information proved valuable, not only to those involved in the Columbia accident investigation, but also to subsequent follow-on work. Analysis consisted of optical microscopy (OM), scanning electron microscopy (SEM), x-ray energy dispersive spectroscopy (EDS), focused ion beam (FIB), transmission electron microscopy (TEM), and x-ray diffraction (XRD). The FIB lift-out method proved to be beneficial in obtaining an information-rich sample representative of the char layer (Figure 2). Specifically the composition, order, and pattern of deposits were examined and analyzed in order to determine the temperature at which particular silicates and inter-metallic compounds were formed. This information, in conjunction with fracture evidence from associated hardware such as elevons and actuators, helped investigators determine the environment experienced during the break up of the orbiter.

The myriad observations made on a thick layer of char atop an innocuous fragment of glass which survived the Columbia tragedy only serves to highlight the wealth of information that lies within her debris. The nature of the incident and subsequent breakup allow both engineers and scientists to glean much needed information, to learn how to not only make our existing space 
flight efforts safer, but to also provide a greater breadth of core knowledge for the next generation of vehicles.

References:

[1] Columbia Crew Survival Investigation Report, National Aeronautics and Space Administration, SP-2008-565, Washington, DC, December 2008.

[2] Columbia Accident Investigation Board (CAIB), Report Volume 1, National Aeronautics and Space Administration, Washington, DC, August 2003

[3] Mayeaux B, McDanels S, et al, Materials analysis: a key to unlocking the mystery of the Columbia tragedy", Journal of Materials, February 2004

[4] Olivas JD, Melroy P, et al, OV-102 thermal pane window debris analysis, part of Spacecraft Crew Survival Integration Investigation Report, NASA

[5] J. D. Olivas, M. C. Wright et al, Acta Astronautica, Crystallographic oxide phase identification of char deposits obtained from space shuttle Columbia window debris; Vol. 67, Issues 5-6, September-October 2010

[6] The Authors would like to thank astronauts Dr. Danny Olivas and Col. Pam Melroy for their endless hours leading the SCSIIT investigations, Rick Russell and Amy Magiacapria for coordinating hardware efforts and their dedication to the Columbia Debris Loan Program, and KSC management and colleagues for their support.

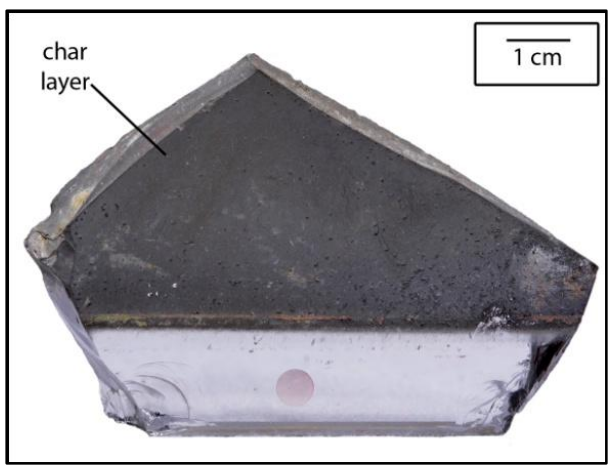

Figure 1. Photograph of glass fragment from one of the recovered Columbia window frames.

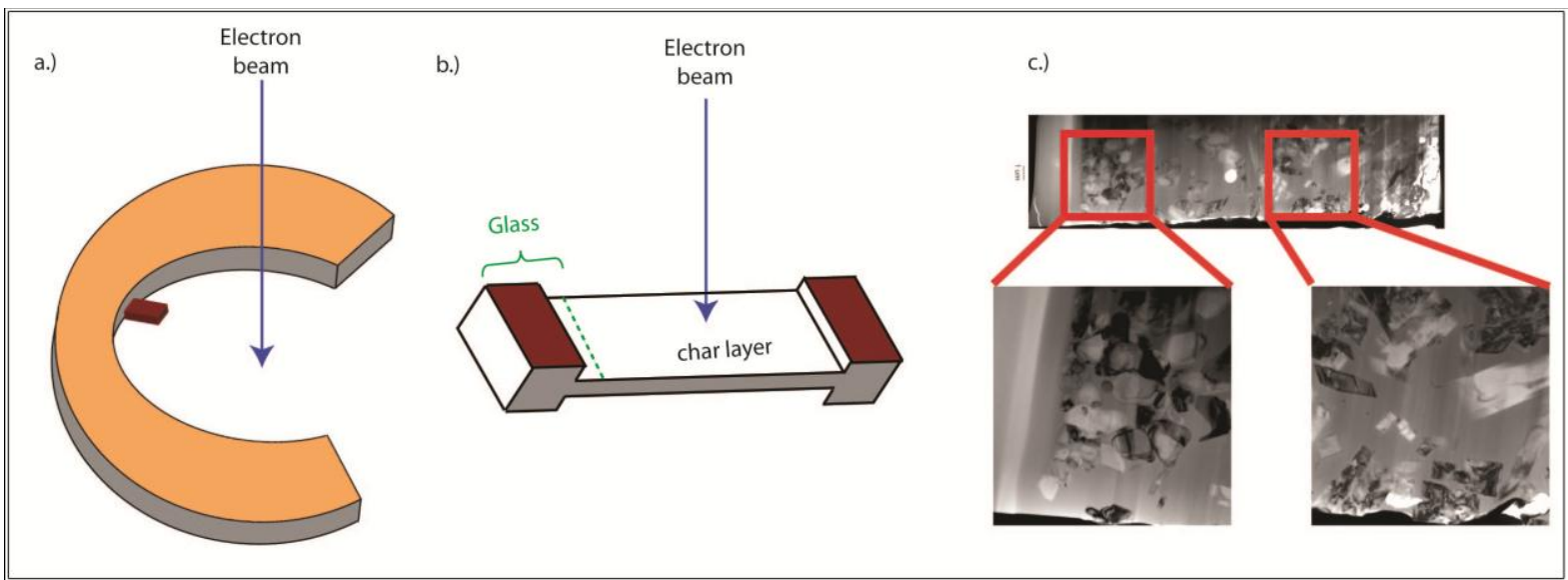

Figure 2. Schematic of char layer specimen created by an in-situ FIB lift-out method on a snipped TEM copper grid (a), "I-beam" specimen detail (b), and resulting TEM images (c). 